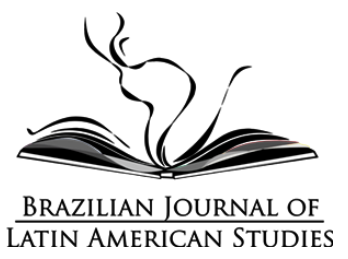

\title{
REGIONALIZAÇÕES DURANTE O PERÍODO DITATORIAL BRASILEIRO
}

\author{
REGIONALIZACIONES EN LA DICTADURA BRASILEÑA \\ REGIONALIZATION DURING THE BRAZILIAN DICTATORSHIP
}

Tainá Siman' (iD

Universidade do Estado do Rio de Janeiro, Brasil

\begin{abstract}
Resumo: $O$ presente artigo tem como objetivo analisar a aproximação e o afastamento do Brasil de diversas regionalizações durante o período da ditadura, levando em conta a formulação da Política Externa Brasileira como ferramenta para explicar a intensidade de determinadas alianças e instituições existentes no período. Para descrever essas tendências regionais, serão levadas em conta as noções da Abordagem do Novo Regionalismo, em que as regiões são construídas, reconstruídas e desconstruídas socialmente pelos autores, discursos, relações e contexto. $\bigcirc$ artigo se apresentará em três partes: o contexto que antecede o início do período ditatorial, a primeira década de ditadura em ascensão (1964-1974), e a segunda década, que já apresenta sinais de transição democrática (1974-1985). Como resultado, se conclui que o movimento das regionalizações passa por um latino-americanismo que envolve uma América continental, chega ao isolamento e completo alinhamento com os Estado Unidos, e acaba por fim repousando em um regionalismo latino-americano mais focado na construção sub-regional do Cone Sul.
\end{abstract}

Palavras-chave: América Latina; Política Externa Brasileira; Ditadura Brasileira; Regionalismo; Integração.

Resumen: Este artículo tiene como objetivo analizar la aproximación y alejamiento del Brasil de diversas regionalizaciones durante el periodo dictatorial, tomando en cuenta la formulación de Política Externa Brasileña como herramienta para explicar la intensidad de determinadas alianzas e instituciones existentes en el periodo. Para describir estas tendencias regionales, se tendrán en cuenta las nociones del enfoque del Nuevo Regionalismo (ANR), en el que las regiones son construidas, reconstruidas y deconstruidas socialmente por los actores, discurso, relaciones y contexto. El artículo presenta tres partes: el contexto que antecede al inicio del periodo dictatorial; la primera década de la dictadura naciente (1964-1974); y la segunda década, que ya presenta indicios de transición democrática

\footnotetext{
${ }^{1}$ Mestranda no Programa de Pós-Graduação em Relações Internacionais da Universidade do Estado do Rio de Janeiro (PPGRI-UERJ); e-mail: taina.siman@gmail.com; pesquisadora do Observatório de Regionalismo (REPRI).
} 
(1974-1985). Como resultado, se concluye que el movimiento de regionalización pasa por un latinoamericanismo que involucra a América continental, llega al aislamiento y completo alineamiento con Estados Unidos, y acaba por fin reposando en un regionalismo latinoamericano más enfocado a la construcción subregional del Cono Sur.

Palabras-clave: América Latina; Política Externa Brasileña; Dictadura Brasileña; Regionalismo; Integración.

Abstract: This article aims to analyze Brazil's approach and distance from various regionalizations during the dictatorship period, taking into account Brazilian Foreign Policy as a tool to explain and interpret the intensity of certain alliances and institutions existent during this period. To describe these regional trends, the notion of New Regionalism Approach (NRA) will be taken, in which regions are socially constructed, reconstructed and deconstructed by the authors, discourses, relationships and context. This article is presented in three parts: the context that precedes the beginning of the dictatorial period, the first decade of rising dictatorship (1964-1974), and the second decade, which already shows signs of democratic transition (1974-1985). As a result, the movement of regional constructions goes through Latin Americanism that covers all continental America, reaches complete isolations and complete alignment with the United States, and finally ends up relying on a Latin American regionalism more focused on sub-regional construction of the Southern Cone.

Key-words: Latin America; Brazilian Foreign Policy; Brazilian Dictatorship; Regionalism; Integration.

DOI:10.11606/issn.1676-6288.prolam.2021.170226

Recebido em: 29/05/2020 Aprovado em: 30/06/2021 Publicado em: 01/07/2021

\section{Introdução}

O Regionalismo tem ganhado grande proeminência dentre os estudos das Relações Internacionais no Brasil nas últimas décadas. Grande parte dessa atenção é resultado da formação do Mercosul (Mercado Comum do Sul) e de outras iniciativas de integração regional, tais como a Unasul (União de Nações Sul-Americanas), que se deram a partir da segunda onda² de integração caracterizada pelo neoliberalismo da década

\footnotetext{
${ }^{2}$ A segunda onda de regionalismo, também chamado de regionalismo aberto, remete a valores neoliberais, ao Consenso de Washington, e à criação de instituições como o Fundo Monetário Internacional (FMI), e ao Banco Mundial. Em contraste, a primeira onda de regionalismo, também chamado de regionalismo fechado, é marcada pelo protecionismo (SOÖDERBAUM, 2015).
} 
de 90 (SODERBAUM 2015). Compreendemos esses fenômenos como resultados das novas interações entre Brasil e Argentina e pelo processo de redemocratização que esses Estados passavam, bem como sua reaproximação da América Latina como um todo. Mas o que acontecia com o Brasil e suas relações regionais antes disso?

A fim de responder essa pergunta será utilizada a abordagem Novo Regionalismo, que compreende que as regiões são socialmente construídas e desconstruídas, devido à atuação dos atores e condições sistêmicas.

A Abordagem do Novo Regionalismo é bem influente, reivindicando que não existem regiões "naturais", mas que essas são construídas, reconstruídas, e desconstruídas -intencionalmente ou não intencionalmente- nos processos de transformação global. Desde que as regiões são construções sociais, nenhuma delas é 'dada', e não há também interesse regionalista dado, mas sim que os interesses e identidade são moldados nos processos de interação e compreensão intersubjetiva. Comparado com a agenda convencional e racionalista, esse tipo de teorização leva a diferentes respostas e metodologias a respeito de por que e como regiões são formadas e consolidadas, por quem e para qual propósito (SÖDERBAUM, 2016:29-30, tradução nossa³).

A Abordagem Novo Regionalismo (ANR) é desenvolvida no início dos anos 2000 por Hettne e Söderbaum (1999), como tentativa de compreender, de maneira mais ampla, as regiões. Assim, enquanto as teorias regionais até então existentes estavam diretamente conectadas com a União Europeia (UE), por ser conhecida no ocidente como a única integração regional (SÖDERBAUM, 2016), a ANR surge em uma tentativa de criar uma abordagem que permita adaptação, leitura e compreensão das regiões como processos em que cada caso, de maneira individual, seja analisado pelas suas próprias características. O regionalismo deixou de ser fechado, então passam a ser necessárias novas abordagens, abertas e flexíveis, que deem conta dessas novas interpretações, novos atores, e

\footnotetext{
${ }^{3}$ Do inglês original: The New Regionalism Approach (NRA) is quite influential, claiming that there are no 'natural' regions, but these are made, remade and unmade-intentionally or non-intentionally- in the process of global transformation. Since regions are social constructions, none are 'given', and there are no given regionalist interests either, but instead the interests and identities are shaped in the process of interaction and intersubjective understanding. Compared to the mainstream and rationalist agenda, this type of theorizing leads to different answers and methodologies regarding why and how regions are formed and consolidated, by whom and for what purpose.
} 
novas regiões, "Resumindo, o Novo Regionalismo é global e pluralístico, comparado com o velho regionalismo, que era Eurocêntrico e limitado (SÖDERBAUM, 2003: 9, tradução nossa ${ }^{4}$ )".

Afim de abarcar essa pluralidade e adaptação, o Novo Regionalismo se apropria de uma teoria também recente nas Relações Internacionais, o construtivismo. Nela, os processos regionais são construídos socialmente através da interação entre os atores, e são também o resultado dessa interação (SÖDERBAUM, 2016). Nesse âmbito as possibilidades são múltiplas, podendo resultar na priorização de outras agendas para além da econômica, estruturas institucionais formais ou informais, participação maior de setores e atores não estatais, entre outros. Nesse caso, cada processo de construção regional é simplesmente o resultado de interação entre os seus atores, que são agentes de construção desse processo. Assim, cada interação se torna única por responder diretamente aos seus criadores, e além disso, não são modelos estáveis e concretos, podendo mudar de forma ao longo do tempo.

Essa nova interpretação oferece também diversas outras consequências. Uma delas é a possibilidade de que essas regiões e arranjos sejam desconstruídos ou mudados. Como não existem regiões naturais, pré-concebidas, ou dadas, elas são compreendidas como processos que podem ser construídos, reconstruídos (modificados) ou desconstruídos ao longo do tempo (SCHULZ; SÖDERBAUM; ÖJENDAL, 2000). Assim, o esvaziamento ou abandono de determinadas instituições regionais pode acontecer não simplesmente pela falha, mas sim pela reorganização dos atores em optar pela construção de determinados processos em detrimento de outros. Se determinados atores responsáveis por conduzir parte do processo mudam de interesse, ou passam a ter seus interesses voltados para outras vias e processos de construção regional, o processo anterior é mudado ou desconstruído (BORZEL, 2011).

\footnotetext{
${ }^{4}$ Do inglês original: In short, the new regionalism is both global and pluralistic, compared to the old regionalism, which was Eurocentric and narrow.
} 
Além disso, cada região tem distintos atores envolvidos em contextos diferentes, que geram interações características. Isso acaba por criar uma regionalização específica que irá responder pelo seu próprio grau de institucionalização (formal e/ou informal), priorização de determinados temas da agenda em detrimento de outros, e valorização de atores estatais ou não-estatais (SÖDERBAUM, 2004). As construções são reflexo dos interesses, ideias e identidades compartilhadas e expressadas pelos atores de forma que esses processos sejam adaptados, customizados e sirvam aos interesses de seus criadores.

Ao levar em conta o contexto, interações e valores dos atores, fazem parte também da leitura do processo de criação e construção dessas regiões uma sensibilidade do contexto histórico e reconhecimento da realidade compartilhada entre esses atores e sua região (em um sentido geográfico) em comum. Mas essas construções não se limitam ao seu entorno geográfico. O nível global é relevante e as regiões não são encapsuladas em seu próprio entorno, dependendo apenas de sua esfera regional em meio ao vácuo, mas sim fazem parte também de um contexto global como interveniente do processo de construção regional no qual estão inseridas. As influências e atores externos também são levados em conta construindo um processo heterogêneo, podendo ter diversas camadas que manifestem diferente graus de institucionalização e aprofundamento em cada nível ou âmbito de regionalização, que podem se complementar ou inclusive competir uns com os outros (SÖDERBAUM, 2004).

Já o conceito de regionalismo aqui é compreendido desde a construção de cooperação através de diálogo não institucionalizado com fins de cooperação, passando por fóruns e órgãos regionais institucionalizados (compreendidos como Organizações Internacionais Regionais), até a formação de integrações regionais (que implicam necessariamente na promoção do livre comércio), desde que essas interações tenham como característica o compartilhamento de um 
mesmo espaço geográfico (SÖDERBAUM, 2016). No caso de ausência dessas instituições formais, se torna importante para o período analisado que seja levada em conta a regionalização, conceito caracterizado pelo aumento de fluxos de intercâmbio e interação ao ponto de maior interdependência dos atores dentro de um determinado entorno geográfico (MALAMUD, 2012); (SARAIVA; HERNÁNDEZ, 2019).

Assim, o presente artigo busca mapear como se deu a aproximação e o afastamento do Brasil de diversas regionalizações durante o período da ditadura, levando em conta a formulação da Política Externa Brasileira durante a época, e compreendendo-a como ferramenta para explicar a intensidade de determinadas alianças e instituições existentes no período. O objetivo do artigo estrutura-se assim em volta da seguinte pergunta: Como se dá e quais são as regionalizações construídas e desconstruídas durante o período da ditadura?

O artigo foi estruturado da seguinte forma: a primeira seção conta com o contexto sistêmico e o ponto de partida de como estavam as relações entre o Brasil e sua questão regional nos anos que antecedem o período autoritário. A segunda seção compreende os primeiros dez anos da ditadura, com os governos de Castelo Branco (1964-1967), Costa e Silva (1967-1969) e Médici (1969-1974), fortemente pautados no chamado "interesse nacional". Já a terceira seção tratará dos outros dez anos, com os governos de Geisel (1974-1979) e Figueiredo (1979-1985) - que comportam pautas energéticas e de recursos naturais -, e tem um foco maior e relevante nas interações com a Argentina.

Essa divisão do período ditatorial pela metade é frequentemente utilizada nos estudos de Política Externa por descreverem uma mudança na questão de interações burocráticas político-militares, mais fortes na primeira década do que na segunda, dividindo seu apogeu e declínio (VIZENTINI, 1998). Foi considerada como importante para a formação de regionalizações a relação do Brasil com os Estados Unidos (caracterizadas 
como uma regionalização americano continental), a relação do Brasil com a América Latina (geograficamente mais composto com a América do Sul, sendo levada em conta a relação com a Argentina como estratégica para a caracterização do regionalismo latino-americano), e a relação do Brasil com o contexto Norte/Sul e multilateralismo.

\section{O momento pré-ditadura: 0 universalismo da pei em detrimento do foco regional}

O governo de Jânio Quadros e João Goulart tinha como marco de sua estratégia a chamada Política Externa Independente (PEI), que, frente à Guerra Fria e tensões Leste/Oeste, opta por uma atuação independente, tendo cooperado com ambos Estados Unidos e URSS, sendo essa ação guiada por interesses próprios e criando uma terceira via a partir do discurso de "desarmamento, descolonização, desenvolvimento". Além disso, em meio aos chamados movimentos pan (pan-americanismo, pan-africanismo, pan-arabismo $)^{5}$, a postura brasileira se destaca ao se afirmar defensora dos direitos de autodeterminação e não intervenção (AMADO 1996).

A regionalização no momento pré-ditadura possui características fortemente conectadas à questão sistêmica: a criação da Comunidade Europeia em 1957 inaugura a primeira onda de regionalismo, o chamado regionalismo fechado ${ }^{6}$ (SÖDERBAUM, 2015), que inspira a criação de diversas outras integrações regionais, tais como a Associação Latino-Americana de Comércio (ALALC), que foi uma tentativa de estabelecer uma Área de Livre Comércio na região. Essa primeira tentativa de integração tem também forte influência do desenvolvimentismo da Comissão Econômica para a América Latina e o Caribe (CEPAL) (BUENO;

\footnotetext{
5 Movimentos de união política regionais, com forte caráter de defesa de interesses em comum, além da valorização e resgate de fatores filosóficos, políticos, culturais e identitários locais.

6 O chamado regionalismo fechado é caracterizado pelo livre comércio intrabloco, e maior detrimento de comércio com países terceiros, marcados temporalmente por iniciativas da década de 50, como a CECA (Comunidade Europeia do Carvão e do Aço), que dá origem à União Europeia, e a ALALC.
} 
RAMANZINI JÚNIOR; VIGEVANI, 2014). Voltadas mais para questões comerciais e abarcando a América Central e o México, essas organizações regionais são motivadas por ideais desenvolvimentistas e um movimento pan-americano que faça frente ao regionalismo hemisférico proposto pelos Estados Unidos a partir da Organização dos Estados Americanos (OEA) ${ }^{7}$ (POLETTO, 1999).

No caso dos Estados Unidos, as relações passam por um determinado ceticismo: o fracasso ${ }^{8}$ da Operação Pan Americana (OPA) não desincentiva o Brasil a assinar a Aliança para o Progresso (1961), que também falha em alcançar os resultados almejados devido ao seu esvaziamento "natural devido às pressões da agenda norte-americana na Eurásia e crises internas à hegemonia, relacionadas nos anos 1960 ao movimento dos direitos civis, o assassinato do Presidente John Fitzgerald Kennedy e ao início da Guerra do Vietnã" (PECEQUILO; ALVES DO CARMO, 2015:13).

A OPA, no entanto, serviu para estreitar as relações especialmente entre Brasil e Argentina, o que culmina nos Acordos de Uruguaiana9 ${ }^{\text {. }}$ então chamado "espírito de Uruguaiana" consistia em uma postura sul americana pautada na cooperação para o desenvolvimento juntamente com determinismo e coordenação de ações e organismos para a projeção da região como conjunto para o meio mundial, que por consequência, era forte o suficiente para superar desavenças inclusive fronteiriças (CORREA

\footnotetext{
7 "Na ordem mundial do segundo pós-guerra, foi prevista na carta da ONU a criação de organismos regionais. Assim, em 1947, foi assinado em Petrópolis o Tratado Interamericano de Assistência Recíproca (TIAR), que previa mecanismos de manutenção da paz e da segurança hemisférica. A Organização dos Estados Americanos (OEA), criada em 1948 pela IX Conferência Internacional Americana, realizada em Bogotá, é a sucessora da União Pan-Americana criada em 1890 e responsável pelas conferências que se lhe seguiram. Com o TIAR e a OEA, o regionalismo hemisférico integrou-se à ordem mundial do segundo pós-guerra" (BUENO; RAMANZINI JÚNIOR; VIGEVANI, 2014:568)

${ }^{8}$ A palavra fracasso foi adotada levando em conta os resultados econômicos esperados pelo Brasil e outros países sul americanos em questão de se alcançar, com a ajuda dos Estados Unidos, o chamado desenvolvimento. É reconhecida a importância da OPA em outros sentidos, tais como a reaproximação entre países latino-americanos e seus derivados: a criação da ALALC, do BID (Banco Interamericano do Desenvolvimento) e os acordos de Uruguaiana.

${ }^{9}$ Série de acordos firmados entre Brasil e Argentina, com o intuito de estreitar as relações políticas, diplomáticas e comerciais entre os dois países.
} 
DA SILVA, 2005). Esse espírito acaba por ser interrompido pelos golpes militares.

Em fóruns multilaterais, a atuação do Brasil é movida por caráter nacional-desenvolvimentista tal como a UNCTAD e o $G 77^{10}$, direcionando o Brasil para uma postura mais universal. Essa universalização não acontece necessariamente em detrimento de uma construção regional, mas nesse contexto específico compreendemos que a forte relação entre desenvolvimento, movimentos pan (acima mencionados), e o caráter de independência da política externa acaba por se sobrepor ao desenvolvimento de iniciativas regionais. Compreendemos, no entanto, que essa questão não se dá somente pelo contexto e condições sistêmicas, mas também pelos interesses dos atores.

\section{Primeiro momento da ditadura: da aproximação multirregional ao alinhamento isolacionista (1964-1974)}

O governo de Castelo Branco, que inaugura o período ditatorial (1964-1985), é caracterizado pela política externa de círculos concêntricos (desenvolvida pelo na época Chefe da Casa Civil, Golbery do Couto e Silva), que por si só já descreve direções em que a questão de inserção regional brasileira vai se direcionar. Em um círculo maior, com nível mais baixo de importância, está a luta contra o comunismo, encadeada pelos Estados Unidos dentro do contexto de Guerra Fria, em que a preocupação estadunidense de manter o restante da América longe da influência comunista irá intermediar as relações do Brasil com os outros países do continente. (MELLO, 1997)

No segundo círculo está o nível médio, o regional, onde se situa a necessidade da política externa em dar importância às relações do Brasil

\footnotetext{
10 O UNCTAD e o G77 são importantes iniciativas no marco das Nações Unidas voltados exclusivamente para países em desenvolvimento. A UNCTAD (Conferência das Nações Unidas sobre Comércio e Desenvolvimento), foi criada como alternativa ao GATT (Acordo Geral de Tarifas e Comércio), promovendo o comércio entre países em desenvolvimento. O Grupo dos 77 é um grupo de 77 países como representação do Sul Global.
} 
com os outros países do continente americano. Conforme os aspectos que serão explicitados a seguir sobre o governo Castelo Branco, a teoria dos círculos concêntricos acaba por explicar em grande parte a dinâmica das tentativas de construção regional durante esse momento: as relações sul americanas têm grande importância dentro desse período, sem nunca perder de vista o contexto simultâneo das interações com os Estados Unidos, que dentro do círculo concêntrico acaba por literalmente rodear essas interações (MELLO, 1997).

Apesar do claro interesse a partir das tentativas do Brasil em estabelecer relações próximas com a América Latina, em especial seus países vizinhos, a crescente influência de Fidel Castro no continente faz com que Castelo Branco rompa as relações diplomáticas com Cuba no intuito de diminuir as tensões com os Estados Unidos. Essa retomada de aliança estadunidense tem um caráter centrado na segurança hemisférica e em um segundo plano, em relações comerciais. Os exemplos dessa relação têm foco na criação da Operação Interamericana de Paz criada pela OEA que, tendo o Brasil como líder latino-americano em número de tropas, conduz a intervenção na República Dominicana em 1965.

Em uma tentativa de fortalecer a ALALC, o Brasil vai tentar se aproximar de países fronteiriços, especialmente Argentina, Paraguai e Bolívia. Com a Bolívia, são assinados acordos de transporte terrestre e fluvial. Com o Paraguai, são superados problemas de fronteiras, seguidos da assinatura da Ata de Cataratas, em que "se iniciava uma verdadeira intervenção cirúrgica no cone sul, de largo alcance político, cimentando uma definitiva aliança com o estado paraguaio" (GONÇALVES; MIYAMOTO, 1993:218). No entanto, a Ata das Cataratas também pode ser considerada outro evento que marca a rivalidade político-econômica entre Brasil e Argentina, já que a bacia hidrográfica compartilhada entre os três países exigia um acordo multilateral ao invés de bilateral (PECEQUILO; ALVES DO CARMO, 2015). 
Com as constantes reformulações de políticas econômicas causadas pela sequência de mudanças de regimes dentro dos países da América Latina, a conjuntura existente no momento não favorecia o desenvolvimento da integração latino-americana, especialmente devido à agravante sensibilidade das relações Brasil-Argentina (países tidos como líderes nessas iniciativas) e sua crescente tensão. Dentro desse contexto, a relação enfrenta algumas apreensões, como a disputa por recursos hídricos que se intensifica em 1967, conforme já mencionado. Outra tentativa que visava o resgate de melhores relações com a Argentina foi a negociação de uma união comercial com o país, plano abandonado já no início da gestão de Costa e Silva. (PECEQUILO, ALVES DO CARMO, 2015). Nessa época se deu também a criação do OPANAL ${ }^{11}$ (Organismo para Proscrição das Armas Nucleares na América Latina e Caribe), que fiscaliza o Tratado de Tlatelolco, referente à proibição de armas nucleares, essencial para a segurança regional.

Por outro lado, podemos notar a política externa de Castelo Branco em dois movimentos, conforme observado por Pinheiro (2000) e Khalil e Alves (2014) um de alinhamento com os Estados Unidos, perceptível pelos discursos públicos do governo e postura oficial do próprio presidente, e outro, conduzido pelo Itamaraty, de continuação da Política Externa Independente, caracterizado pelas relações com o sul global e aproximação de parceiros não convencionais.

Em alguns casos, ocorreu mesmo o aprofundamento da relação. No governo Castelo Branco, foram assinados, ao todo, 24 atos internacionais com países integrantes do Terceiro Mundo, o que corresponde a $46 \%$ do total de atos internacionais assinados pelo Brasil, um grande salto comparado aos governos Quadros e Goulart, com 25\%). O aumento absoluto e relativo foi acompanhado de uma pequena, mas importante, diversificação de parceiros. Foram assinados três atos internacionais com países africanos, um com Camarões e dois com Senegal, nos dois casos sobre comércio. Nenhum ato internacional havia sido assinado com países do continente africano nos cinco governos anteriores (KHALIL; ALVES, 2014:695).

\footnotetext{
"Criado para a promoção da não-agressão e a favor do desarmamento nuclear entre países da América Latina e Caribe
} 
Assim, o Itamaraty, por ter herdado e institucionalizado parte da PEI, acaba por continuar dentro da mesma linha de atuação, destoando do discurso da política externa presidencial e mais focado em se alinhar de maneira multilateral às ex-colônias da Ásia e da África em fóruns direcionados ao Terceiro Mundo. Essa articulação é institucionalizada a partir de uma construção regional do hemisfério do sul, que irá compor o G77. Outro exemplo é a criação da UNCTAD (Conferência das nações Unidas sobre o Comércio e Desenvolvimento, sem sigla em português), que surge em contrapartida ao GATT (Acordo Geral sobre Tarifas e Comércio, também sem sigla em português), que atenderia aos interesses do hemisfério norte.

Por fim, na política externa do governo Castelo Branco se destaca a observação de duas tendências regionais: uma regionalização horizontal, marcada pela recente intensificação de relações entre o hemisfério sul, característica herdada pelo caráter de inovação da PEI; e uma regionalização americana vertical de dimensões continentais, caracterizada pelas preocupações relativas à segurança dos Estados Unidos, supervisionando a sub-região do Caribe, da América Central e América do Sul.

Os anos de governo de Costa e Silva (1967 a 1969) indicam o início da chamada ditadura linha-dura, definida por maiores índices de repressão, exemplificado pela dissolução do legislativo através do Al-5 em 1968. A partir de então, ideais de nacionalismo e desenvolvimento também vão adquirir prioridade na agenda nacional. Como a Operação Pan-Americana não rendeu os resultados econômicos esperados de uma cooperação com os Estados Unidos, o Brasil decide por colocar o desenvolvimento como o principal objetivo de governo (GONÇALVES; MIYAMOTO, 1993: 218).

Isso significa adotar uma postura mais distanciada dos Estados Unidos devido ao ceticismo de que esse bilateralismo traria de fato vantagens ao Brasil. A política externa do período é então a chamada 
Diplomacia do Interesse Nacional, que busca alianças interestatais multilaterais que tragam ao país desenvolvimento industrial e econômico. Essa postura acaba por ser vista pelos Estados Unidos como um distanciamento, agravado por disputas comerciais: "Em 1969, termos como "rivalidade emergente", "o relacionamento perdido" e "conflito administrado" passam a ser aplicados com mais frequência à relação bilateral." (PECEQUILO; ALVES DO CARMO, 2015:17).

Tratamento igual é dado ao relacionamento brasileiro com outras regiões. Sendo assim, muito voltado para o ambiente interno, o Brasil não desenvolve com a mesma força nenhuma relação de caráter explicitamente regional, buscando parceiros pontuais que ofereçam ao Brasil oportunidades boas para o desenvolvimento e o chamado interesse nacional (GONÇALVES; MIYAMOTO, 1993). Além disso, o distanciamento da PEl e dos movimentos terceiro-mundistas é marcado pelo apoio a Portugal contra as colônias, que foi uma postura adotada ainda no governo Castelo Branco.

Tendo como pano de fundo o "milagre econômico" e mantendo o alto grau de autoritarismo do início da década de 70, o governo Médici pauta a relação entre o desenvolvimento nacional e a política externa em uma dinâmica diferente da observada no governo Costa e Silva. A política externa de Médici, que conectava planos de desenvolvimento nacional à diplomacia, busca utilizar-se do crescimento político-econômico do país como forma de se destacar no cenário mundial, desencadeando a ideia do "Brasil potência" (SARAIVA, 1998).

Nesse movimento, o Brasil busca uma maneira de se desvincular do grupo de países subdesenvolvidos, o que faz com que os resquícios da PEI que antes eram perceptíveis na aproximação com países subdesenvolvidos mudem de lógica: agora o papel do Brasil na relação com esses países se destaca em um sentido de liderança, em que ele seria a voz ativa no nível internacional dos interesses desses países e sua busca pelo 
desenvolvimento. Essa postura, no entanto, é recebida com desconfiança e descrença.

Essa mudança de atitude pauta em grande medida como o relacionamento com a América Latina e com os Estados Unidos é conduzido. A eleição de Salvador Allende no Chile propicia até determinado ponto um realinhamento a partir da convergência entre Brasil e EUA, reforçando o interesse dos EUA em posicionar o Brasil como um forte aliado no papel de combater regionalmente o comunismo. Assim, a nova aliança em promover o Brasil como líder regional é vista com precaução pelos demais países da América Latina, especialmente Uruguai e Bolívia, frente à possibilidade de uma intervenção no intuito de prevenir que o comunismo se espalhe pela região. (GONÇALVES; MIYAMOTO, 1993).

O Brasil é então acusado de conduzir e participar em diversas tentativas e apoiar ações intervencionistas, como a Operação 30 Horas no Uruguai, o golpe da Bolívia (em 1971) e o golpe do Chile (em 1973) (CASTILHO, 2014). Com a Argentina, a relação se complica ainda mais nesse período de governo, principalmente em torno do assunto de recursos energéticos da Bacia do Prata (SPEKTOR, 2002). O acordo bilateral, entretanto, acabou por definir a relação, que se manteve cooperativa com o Paraguai, a partir do Tratado de Itaipu.

\begin{abstract}
Entre 1967 e 1973, as relações argentino-brasileiras assistiram a um grau de deterioração raramente visto em sua história. Devido à definição do regime contemporâneo para a utilização do caudal hídrico da Bacia do Prata, o vínculo bilateral foi vítima de um confrontacionismo que se espalhou por ambas as sociedades e terminou turvando os projetos conjuntos de complementação econômica e cooperação técnica que o espírito de Uruguaiana ambicionara. Ao longo desses seis anos, ganhou força uma vertente inédita na diplomacia brasileira contemporânea: a diluição da cordialidade oficial como opção perene nos negócios com o governo argentino. (SPEKTOR, 2002:126)
\end{abstract}

No cenário multilateral, o Brasil busca novos parceiros comerciais a fim de expandir o mercado a partir da exportação de matérias primas, com foco também nos produtores de petróleo, colocando embaixadas em 
diversos países do Oriente Médio. Acordos de cooperação seriam também firmados nessa época com países da África, que teriam um foco comercial, mas também estratégico na questão de segurança energética. (GONÇALVES; MIYAMOTO, 1993).

O posicionamento brasileiro regionalmente é percebido como uma força aliadas aos Estados Unidos e uma extensão do seu braço de interesse do norte para o sul' ${ }^{12}$, buscando assim uma maneira de se destacar no cenário internacional como um líder sul-americano. Essa regionalização atrelada aos Estados Unidos se opõe à construção da integração regional latino-americana pautada em interesses e problemas sul americanos em comum, que definiam o chamado "espírito de Uruguaiana" presente no início do período ditatorial. As relações com o resto do hemisfério sul, nesse momento, destacadamente Oriente Médio e África, são também fortemente pautadas em aspectos geopolíticos relacionados à segurança (quanto ao poder marítimo e energético, respectivamente).

\section{Segundo momento da ditadura: reaproximação regional e abordagem universal}

O governo Geisel, que indica o início da chamada segunda fase da ditadura, simbolizada pela crise na questão político-diplomática, apresenta determinado desencanto dos termos nos quais a relação com os Estados Unidos foi construída do período anterior. Não gozando mais do crescimento econômico e já em frente da que seria a crise da dívida externa, o governo Geisel tem sua política externa caracterizada pelo chamado Pragmatismo Responsável ${ }^{13}$.

\footnotetext{
${ }^{12}$ Aqui, faz-se referência ao chamado "offshore balancing", a estratégia de grande potência de se utilizarem de potências regionais para se afirmarem (e defenderem seus interesses) naquela região (MEARSHEIMER; WALT, 2016)

${ }^{13} \mathrm{Em}$ contexto de Guerra Fria, o Pragmatismo Responsável significa a adoção de um discurso de uma Política Externa "livre de ideologia", ou seja, marcada pela busca por novos parceiros, se afastando de adotar uma posição ideológica entre Estados Unidos e URSS.
} 
Quando o esforço de construir relações fortes com grandes potências não tem o resultado esperado pelo governo brasileiro, e frente à possibilidade do isolamento internacional, o Brasil prefere pela mudança de estratégia, simbolizada pela retomada das relações com governos em seu entorno latino-americano. No entanto, devido aos acontecimentos durante o governo anterior, essa reaproximação é recebida com certa desconfiança.

A principal dificuldade com que a diplomacia brasileira se defrontava era a referente à carga histórica que pesava sobre essas relações. A fronteira comum com a maioria das nações do continente obrigava a que a mudança de política se desse de maneira mais criteriosa. Sobretudo porque a imagem projetada no decurso dos governos militares era a de um Brasil movido por apetites hegemônicos. A reversão desse quadro de dificuldades dependia tanto da habilidade diplomática em apresentar uma agenda que contemplasse interesses mútuos, como do governo brasileiro em definir objetivamente seus próprios interesses (GONÇALVES; MIYAMOTO, 1993:235).

Porém o diálogo amigável é reestabelecido com a Argentina, e ainda que o principal entrave -a questão da Bacia do Prata e o Itaipu- não seja resolvido nesse período, as intensas negociações e diálogos (dos quais também participa o Paraguai) demonstram progresso e interesse dos dois governos. Dentro da iniciativa latino-americana também é realçada a assinatura do Tratado de Cooperação Amazônica ${ }^{14}$, destacando a importância do regionalismo transnacional, trazendo a cooperação regional para a utilização soberana e harmonia entre proteção ecológica e exploração a favor do desenvolvimento (CORREA DA SILVA, 2005).

Além disso, em outro movimento de integração regional vai ser criado em 1975 o Sistema Econômico Latino-Americano e do Caribe ${ }^{15}$, a fim de contribuir para a autonomia da região dentro do sistema internacional, em um contexto de crise da dívida externa da Guerra das Malvinas (1982)

\footnotetext{
${ }^{14}$ Acordo firmado entre Brasil, Bolívia, Colômbia, Equador, Guiana, Peru, Suriname e Venezuela, com o objetivo de conjugar, em equilíbrio, o desenvolvimento econômico e preservação do meio ambiente em território amazônico.

${ }^{15}$ Foro para a cooperação e adoção de estratégias econômicas para os países da região
} 
(ESTENSSORO, 1994). As atividades da ALALC também vão retomar o mesmo vigor de antes a partir do final de 1978.

Essa aproximação do Brasil com o entorno latino-americano, dentro da dinâmica da Guerra das Malvinas e a crise da dívida externa, acaba por afastar o país das relações com os Estados Unidos, gerando tensões nos âmbitos econômicos e políticos. Mesmo após o afastamento, a relação entre Brasil-EUA continua demarcada por tensões pela não discordância em assuntos econômicos, fazendo com que esse seja o momento de maior não-alinhamento desde o início da ditadura.

Com o intuito de abandonar o isolamento, essas políticas acabam por aproximar o Brasil de novas parcerias, cenário no qual as relações multilaterais continuam e ganham maior horizontalidade, aproximando mais o Brasil da África (principalmente as ex-colônias) e Ásia (principalmente China e Japão). As relações com a China são assim retomadas, e o país declara apoio às independências de ex-colônias portuguesas como Angola e Guiné Bissau (em 1975 e 1974, respectivamente), o que atende a interesses econômicos e diplomáticos, destacando o Brasil novamente como um dos poderes do hemisfério sul. (GONÇALVES; MIYAMOTO, 1993)

É necessário recordar, no entanto, que a postura brasileira foi possível graças à adoção do pragmatismo, ou seja, a política externa desvinculada de questões ideológicas ${ }^{16}$, visando apenas laços de cooperação a favor do desenvolvimento nacional. Dentro desse contexto foi possível afastar-se dos Estados Unidos e reaproximar-se da América Latina exercendo uma postura de liderança no hemisfério sul que é recebida pelos países vizinhos com maior legitimidade, inclusive retomando planos de integração.

Considerado como transição entre a ditadura e a democracia, o governo Figueiredo adota uma política externa de caráter universalista, que

\footnotetext{
${ }^{16}$ Aqui compreende-se como "postura pragmática" não o comportamento adotado na política externa, mas sim o discurso construído para a justificativa das decisões que se declaram pragmáticas. A adoção desse pragmatismo responsável é explicada por autores como Lima e Moura (1982), além de Spektor (2004).
} 
tende para a mundialização do sistema internacional como o reconhecimento de um espaço que engloba novas nações para além do antigo mundo europeu. Essa lógica acaba por pautar o reconhecimento da região latino-americana pelo Brasil e transformá-lo, junto com as relações com a Argentina, em prioridade.

Assim, logo no primeiro ano do governo de Figueiredo é assinado o Acordo Tripartite Itaipu-Corpus (1979), que resolve a disputa da Bacia do Prata, inaugurando uma nova fase nas relações entre Brasil e Argentina que, diferente da relação de cordialidade anterior, inaugura uma nova aproximação da qual surgem novas iniciativas de integração (SPEKTOR, 2002). De forma que em 1980, é inaugurada a Associação Latino-Americana de Integração (ALADI), que substitui a ALALC, tendo como objetivo o crescimento econômico e desenvolvimento através da criação de um mercado comum.

A preocupação do status da relação com os Estados Unidos ressurge a fim de evitar maiores tensões. O esvaziamento do TIAR e da OEA traz um esforço por parte do Brasil de manter o grupo operante a favor da participação dos Estados Unidos e do reconhecimento da importância das relações para com o país. Por outro lado, a iniciativa estadunidense de estabelecer a Operação de Tratado do Atlântico Sul (OTAS), em moldes semelhantes aos da OTAN, de forte caráter anticomunista) é rejeitada pelo Brasil.

Na questão multilateral, as relações com a África são aprofundadas principalmente a partir do grande crescimento no número de embaixadas no continente, além da primeira viagem diplomática de um presidente brasileiro (em 1983) pelo continente africano. As relações foram fortalecidas também com o Oriente Médio e a Ásia, mas também com a Europa.

\section{Discussões e considerações finais}


É possível perceber, a partir de uma análise da Política Externa de cada governo da ditadura no Brasil, um movimento de desconstrução e reconstrução de regionalizações a partir da intensificação e distanciamento de determinados parceiros regionais. As conclusões a seguir serão divididas nas três regionalizações analisadas ao longo desse capítulo: da América continental (pautado nas relações com os Estados Unidos), do latino-americano, e do hemisfério sul.

Quanto à regionalização latino-americana pudemos observar que o contexto em que se dá a criação do Mercosul com uma dinâmica já presente no fim do período ditatorial difere grandemente das relações latino-americanas de antes da ditadura. Primeiramente, é interessante notar como o Brasil foi construindo relações entre cada um dos países de sua fronteira, especialmente durante o governo Geisel. Em segundo lugar, é importante notar que dois atores desempenham um papel primordial na diferença de como se dá essas interações na América Latina: Estados Unidos e Argentina.

No caso dos Estados Unidos, devido ao contexto do início do período pré-ditatorial e ao longo do período da ditadura, é possível perceber que a regionalização na América Latina se desenvolve sempre com grande cautela sobre as impressões estadunidenses sobre a região e suas instituições. Somente no governo Figueiredo, em que o Brasil demonstra autonomia frente aos Estados Unidos de maneira pragmática, é que essa relação parece adotar livremente uma identidade em prol dos interesses exclusivos latino-americanos, com a construção de instituições nas quais os Estados Unidos não participem. Isso reflete também em sua própria configuração geográfica: a integração do período pré-ditatorial abarcava por vezes todo o continente latino-americano, e depois é construído focado apenas na América do Sul ou na subdivisão do Cone Sul.

As relações com a Argentina também parecem ser centrais na construção dessa regionalização: a postura de cordialidade e rivalidade 
entre e o Brasil e a Argentina antes e durante toda a primeira fase da ditadura faz com que a desconfiança enfraqueça o potencial cooperativo para a região, e atinge o seu ápice no governo Médici, junto com o maior ponto de desconstrução da regionalização latino-americana. As interações no período ditatorial são dominadas pelo impasse na questão da Bacia do Prata, e somente quando essa questão é superada (como é bem descrito por Spektor, 2002) é que se inaugura um novo tipo de interação que torna possível a criação do Mercosul.

A relação junto ao hemisfério sul é compreendida de duas maneiras. Uma compreende a postura multilateral brasileira como forma de encontrar um meio termo, baseado na resistência e autonomia no sentido de não alinhamento com os Estados Unidos, mesmo frente às pressões e tensões da Guerra Fria. Essa relação permitirá ao Brasil exercer um papel de destaque no cenário internacional, sem que esse destaque seja pautado nos interesses de construir uma regionalização latino-americana em detrimento da posição dos Estados Unidos dentro do mesmo continente. Por outro lado, essa aproximação brasileira, ao se espalhar e fortalecer ao longo da Ásia e o Oriente Médio, além das relações já tradicionais com a África, acabam por também levantar severas críticas no governo Figueiredo, devido ao temor de que uma forte construção de relações com países do hemisfério norte acabe por não ser bem vista pelo hemisfério sul (FERREIRA, 2006). Essa é uma hipótese sobre por que essa construção regional sul-sul já existente tem suas relações limitadas e acaba por não evoluir ou por não atingir maiores graus de proximidade.

Já a relação com os Estados Unidos se diferencia grandemente devido ao contexto e o esvaziamento do TIAR e da OEA conforme acontecimentos no fim do período, e sendo essas instituições que pautaram fortemente o pré-ditatorial, o enfraquecimento dessa relação é visto como uma menor preocupação dos Estados Unidos sobre a previsibilidade das relações internacionais. A maneira como o Brasil 
adquire autonomia, se esquivando do viés alinhamento/não alinhamento com os Estados Unidos, também pode ser observada ao longo do processo aqui narrado. Também é importante notar que a reaproximação intencional do Brasil para os Estados Unidos se deve à importância desse país como parceiro comercial e sua hegemonia no sistema. Essa nova aproximação também marca um novo tipo de relação entre esses dois países, possível graças à autonomia adquirida pelo Brasil.

No entanto, as construções regionais do Brasil com a América Latina se diferem também de como eram no início e no final do período ditatorial. Na primeira fase, o Brasil caminhava em direção à regionalização de uma América continental e buscava aproximação de uma grande América Latina junto com a inauguração de novas alianças no hemisfério sul. Em seguida, caracterizado pelo crescimento de tensões na relação Brasil-Argentina, motivado por aspirações hegemônicas, pode ser observado o alinhamento estadunidense e o descolamento do eixo sul, levando à um movimento de desconstrução das regionalizações antes existentes, colocando o Brasil em posição isolada. Já na segunda fase, a autonomia frente aos Estados Unidos é conquistada, as relações dentro do Cone Sul ganham horizontalidade de maior proximidade, e parceiros chave ao longo de todo o hemisfério sul são apontados.

Como resultado, podemos observar que nenhuma das relações que é reconstruída antes a ao final do período ditatorial é reconstruída da mesma forma, sendo altamente dependentes do contexto e das relações com outros atores. É possível também ressaltar a importância da percepção de dois atores que interferem fortemente na construção dessas regionalizações, os Estados Unidos e a Argentina. O Brasil aparece também como um ator pivô para a América Latina, já que as construções regionais são em grande parte lideradas por ele, dependem de sua relação com os Estados Unidos, sua postura e suas ambições, chegando a ser visto como desconfiança ou até mesmo ameaça para países vizinhos. 
Dessas reflexões, surgem outras perguntas, sobre temáticas pouco exploradas: de que forma as percepções dos Estado Unidos sobre a região interferem nas construções regionais possíveis para o continente? Ou ainda: o que o estudo da PEB nos diz sobre construções das quais dependem a região latino-americana? O Brasil enfrenta uma escolha de estratégias entre de destacar individualmente e se destacar a partir da integração, ou essas duas estratégias podem ser complementares? Apesar dessa pesquisa ter sido desenhada para compreender a quase ausência de iniciativas de construção regional presente como um vazio entre ALALC e o Mercosul, acabaram-se por levantar questões que podem ser chave para melhor compreender diversas consequências sobre quais são os regionalismos possíveis e existentes nos dias de hoje.

\section{Referências}

AMADO, Rodrigo. A Política Externa no governo João Goulart. In: José A. G. de Albuquerque (org.). Sessenta Anos de Política Externa Brasileira, 1930-1990, São Paulo: Núcleo de Pesquisa em Relações Internacionais da USP/Cultura Editores Associados. vol. 1. 1996.

BORZEL, Tanja A. Comparative Regionalism: a New Research Agenda. KFG Working Paper Series, No. 28, Freie University Berlin. Agosto, 2011. Disponível em: <https://www.researchgate.net/publication/239806879_Comparative_Regio nalism_-_A_New_Research_Agenda> . Acesso em 15 Jul. 2019.

BUENO, Clodoaldo; RAMANZINI JÚNIOR, Haroldo; VIGEVANI, Tullo. Uma perspectiva de Longo Período sobre a Integração Latino-Americana vista pelo Brasil. Contexto int., Rio de Janeiro , v. 36, n. 2, p. 549-583, Dec. 2014. DOI: 10.1590/S0102-85292014000200008.

CASTILHO, Alessandra Beber. O golpe de 1964 e a política externa brasileira dentro do contexto repressivo. Revista NEIBA, Vol. 3, No 1, Novembro 2014. DOI: https://doi.org/10.12957/neiba.2014.13849

CORREA DA SILVA, Vera Lúcia. Da Operação Pan-Americana aos Entendimentos de Uruguaiana.: as relações Brasil-Argentina (1958-1962). Orientadora: Dra, Heloísa Conceição Machado da Silva. 2005. 127 pp. Dissertação - Programa de Pós-Graduação em Relações Internacionais, Universidade Federal do Rio Grande do Sul, Porto Alegre, 2005. Disponível 
em: < http://www.lume.ufrgs.br/bitstream/handle/10183/5851/000521288.pdf >. Acesso em 15 Jul. 2018.

ESTENSSORO, Luis E. R. O Sistema Econômico Latino-Americano (SELA): integração e relações internacionais (1975-1991). Orientador: Dr. Paulo César Milone. 1994. 200 p. Dissertação - Programa de Pós-Graduação em Integração Latino-Americana, Universidade de São Paulo, São Paulo, 1994. Disponível

em: <http://www.teses.usp.br/teses/disponiveis/84/84131/tde-16082011-100208/pu blico/1994_LuisEnriqueRambalducciEstenssoro.pdf>. Acesso em 09 Ago. 2018.

FERREIRA, Túlio Sérgio Henriques. A ruína do consenso: a política exterior do Brasil no governo Figueiredo (de 1979 a 1985). Revista Brasileira de Política Internacional, Brasília, Vol. 49, No. 2, p. 119-136, 2006. Disponível em: <https://www.scielo.br/scielo.php?script=sci_abstract\&pid=S0034-73292006 000200007\&lng=en\&nrm=iso\&tlng=pt>. Acesso em 12 Dez. 2020.

GONÇALVES, Williams da Silva; MIYAMOTO, Shiguenoli. Os militares na política externa brasileira: 1964-1984. Revista Estudos Históricos, São Paulo, Vol. 6, No. 12, p. 211-246, 1993. Disponível em: < http://bibliotecadigital.fgv.br/ojs/index.php/reh/article/view/1964>. Acesso em 12 Jul. 2018

HETTNE, Björn; SÖDERBAUM, Fredrik. Towards Global Social Theory. Journal of International Relations and Development, Vol. 2, No. 4, p. 358-368, Dezembro, $1999 . \quad$ Disponível em: <https://papers.ssrn.com/sol3/papers.cfm?abstract_id=2399203>. Acesso em 12 Dez. 2020.

KHALIL, Suhayla; ALVES, Vágner Camilo. Ideias e Política Externa: As relações do Brasil com o Terceiro Mundo durante o governo de Castelo Branco. Contexto int. Rio de Janeiro, Vol. 3, 6 No. 2, Julho/Dezembro 2014. 2014. DOI: 10.1590/S0102-85292014000200012

LIMA, Maria Regina Soares de; MOURA, Gerson. A trajetória do pragmatismo - Uma análise da Política Externa Brasileira. DADOS, Rio de Janeiro, Vol. 24, No. 3, p. 349- 363, 1982. Disponível em: <https://edisciplinas.usp.br/pluginfile.php/118080/mod_resource/content/1/ Maria\%20Regina\%20Soares\%20de\%20Lima.pdf>. Acesso em 12 Dez. 2020.

MALAMUD, Andrés. Conceptos, teorías y debates sobre la integración regional. BJIR, Marília, Vol. 1, No. 3, p. 367-397, Set/Dez. 2012. https://doi.org/10.36311/2237-7743.2012.v1n3.p366-389 
MEARSHEIMER, John J.; WALT, Stephen M. The Case for Offshore Balancing. Foreign Affairs: America and the World.Julho/Agosto 2016. Disponível em:

<https://www.foreignaffairs.com/articles/united-states/2016-06-13/case-offsh ore-balancing>. Acesso 20 Nov. 2010.

MELLO, Leonel Itaussu de Almeida. Golbery do Couto Silva e o "Destino Manifesto" Brasileiro. In: A Geopolítica do Brasil e a Bacia do Prata. Manaus: Universidade do Amazonas, 1997.

PECEQUILO, Cristina Soreanu; ALVES DO CARMO, Corival. O Brasil e a América do Sul: Relações regionais e globais. Rio de Janeiro: Alta Books, 2015.

PINHEIRO, Letícia. Unidades de decisão e processo de formulação de política externa durante o regime militar. In: J. A. G. de Albuquerque (org.), Sessenta anos de política externa brasileira (1930-1990): Prioridades, Atores e Políticas. São Paulo, Annablume/Nupri, Vol 4. 2000. p.449-474.

POLETTO, Dorivaldo Walmor. A CEPAL e a América Latina. Estudos Ibero-Americanos, Rio Grande do Sul, Vol. 25, No. 1, p 209-216, Junho 1999. Disponível em:

https://revistaseletronicas.pucrs.br/ojs/index.php/iberoamericana/article/do wnload/25570/14941>. Acesso em 15 Jul. 2018

SARAIVA, Miriam Gomes. Política externa, política interna e estratégia de desenvolvimento: o projeto de Brasil potência emergente (1974 a 1979). Sociedade em Debate. Vol.4 No.1. Pelotas/RS: Universidade Federal de Pelotas, Abr. 1998. p.19-38.

SARAIVA, Miriam Gomes; HERNÁNDEZ, Lorena Granja. La integración americana en la encrucijada entre la ideología y el pragmatismo. Revista Uruguaya de Ciencia Política Vol. 28 No. 1. 2019. DOI: 10.26851/RUCP.28.1.6

SCHULZ, Michael; SÖDERBAUM, Fredrik; ÖJENDAL, Joakim. Regionalisation in a Globalising World. A Comparative Perspective on Actors. 2000. Disponível em: https://www.researchgate.net/publication/259580865_Regionalisation_in_a_ Globalising_World_A_Comparative_Perspective_on_Actors_Forms_and_Pro cesses>. Acesso em 21 Jun. 2019.

SÖDERBAUM, Fredrik. Introduction. In: SÖDERBAUM, Fredrik; SHAW, Timothy (Eds). Theories of New Regionalism. London: Palgrave Macmillan, 2003.

SÖDERBAUM, Fredrik. Early Old and New Regionalism: The Scholarly Development of the Field. KFG Working Paper Series, No. 64, Freie University Berlin. Outubro $2015 . \quad$ Disponível em: 
<http://www.polsoz.fu-berlin.de/en/v/transformeurope/publications/working _paper/wp/wp64/WP-64-Soederbaum.pdf>. Acesso em 12 Ago. 2018.

SÖDERBAUM, Fredrik. Rethinking Regionalism. London: MacMillan Education, 2016.

SPEKTOR, Matias. O Brasil e a Argentina entre a cordialidade oficial e o projeto de integração: a política externa do governo de Ernesto Geisel (1974-1979). Rev. Bras. Polit. Int. Vol. 25, No. 1, p.117-145, 2002. Disponível em: <http://www.scielo.br/pdf/rbpi/v45n1/a05v45n1.pdf>. Acesso em 06 Ago. 2018.

SPEKTOR, Matias. Origens e direção do Pragmatismo Ecumênico e Responsável (1974-1979). Revista Brasileira de Política Internacional, vol.47, n.2. Brasília, 2004.

VIZENTINI, Paulo Fagundes. A Política Externa do Regime Militar Brasileiro. Porto Alegre: Editora UFRGS, 1998. 